Journal of Education and Vocational Research (ISSN 2221-2590)

Vol. 6, No. 4, pp. 59-65, December 2015

\title{
A study of transferable skills for Work based Learning (WBL) Assessment
}

\author{
Abdool Qaiyum Mohabuth \\ Centre for Innovative \& Lifelong Learning, University of Mauritius, Reduit, Mauritius \\ a.mohabuth@uom.ac.mu
}

\begin{abstract}
Transferable skills are learnt abilities which are mainly acquired when experiencing work. University students have the opportunities to develop the knowledge and aptitude at work when they undertake WBL placement during their studies. There is a range of transferable skills which students may acquire at their placement settings. Assessing the achievement of students on practice learning based on the transferable skills is regarded as being complex and tedious due to the variability of placement settings. No attempt has been made in investigating whether these skills are assessable at practice settings. This study seeks to define a set of generic transferable skills that can be assessed during WBL practice. Quantitative technique was used involving the design of two questionnaires. One was administered to University of Mauritius students who have undertaken WBL practice and the other was slightly modified, destined to mentors who have supervised and assessed students at placement settings. To obtain a good representation of the student's population, the sample considered was stratified over four Faculties. As for the mentors, probability sampling was considered. Findings revealed that transferable skills may be subject to formal assessment at practice settings. Hypothesis tested indicate that there was no significant difference among male and female as regards to the application of transferable skills for formal assessment. A list of core transferable skills that are assessable at any practice settings has been defined after taking into account their degree of being generic, extent of acquisition at work settings and their consideration for formal assessment. Both students and mentors assert that these transferable skills are accessible at work settings and require commitment and energy to be acquired successfully.
\end{abstract}

Keywords: Knowledge, Skills, Assessment, Placement, Mentors

\section{Introduction}

Academics have to cope with increasing issues as regards to the assessment of competences of students due to the exigencies of employers about skills capabilities of fresh graduates. Nabi (2003) showed it is the portfolio of skills which a graduate could offer to an employer that makes the differentiating factor in gaining employment. This is causing a re-examination of assessment practices to include assessment of students' transferable skills besides the academic content of what students are studying. All of this is leading to the development of new assessment methods, giving rise to the need for greater than ever ingenuity and flexibility, while still monitoring and assuring the quality of the process. Many Universities are thus considering the importance of assessing transferable skills which students acquired when they are undertaking WBL practice. New teaching and learning strategies are being developed to ensure that students become more aware of the demands of future employers for graduates who are able to display a range of personal transferable skills. Employers required individuals who possess a variety of competences in addition to intellectual ability. Communication and presentation skills, problem-solving and time management, teamwork and leadership skills are now being given due consideration to be incorporated into degree courses. Several studies have tried to identify a core set of transferable skills which students can acquire at their placement settings. However, the different lists proposed have often been criticized for being exhaustive and duplicative. While Universities recognized that these transferable skills are more accessible at placement settings rather than thru on-campus courses, they experienced difficulty in setting the proper structure for assessing these skills. The workplace is found to be the best site where students can acquire transferable skills to make them fit for purpose and practice (Zegwaard \& Coll, 2011). The challenge is to establish a set of generic core transferable skills on which assessment may be based whist taking into account the tremendous variation in placement settings with differing employers and mentors. 


\section{Literature Review}

In recent times there has been an emphasis on embedding generic skills development into teaching programs within degree studies (Oliver et al., 2008), given the increased emphasis on the importance of generic skills in gaining employment (Finch et al., 2013). There is general agreement that generic transferable skills are those skills that are required to be competent in any discipline, including analytical and problem solving skills (Nunan et al., 2000). However, there is still a widespread debate on what constitutes generic transferable skills (e.g. Barrie, 2006; Bridgstock, 2009; Fallows and Stevens, 2000). Fallows and Stevens (2000) defined transferable skills as those skills that someone has acquired and developed through one situation and are useful when transferred into another (next career). In fact, transferable skills are those versatile skills acquired during WBL practice which students initially developed, applied and made use of in a number of different ways. Harvey et al. (1997) and Te Wiata (2001) found that students' ability to integrate and demonstrate generic skills was linked to the development of confidence in their application to new and different contexts, including the workplace. The Department for Education and Skills (DfES, 2005) has defined the transferable skills as "essential skills which people need in order to function effectively as members of a flexible and competitive workforce". The DfES, identified six key skills which are: communication, application of number, information technology, working with others, improving own learning and performance, problem solving. But, this list is found to be inadequate for assessment as students are exposed to a greater range of transferable skills on practice. Kelly (2001) described the key skills as generic transferable skills that contribute to individual effectiveness, flexibility and adaptability within the labor market. Student learning in placements has been described as being problematic and influenced by a myriad of contextual factors (Eames, 2010; Johnston, Angerilli, \& Gajdamaschko, 2004). The learning environment differs, but yet Universities and Employers wish to see rigorous application of assessment in WBL practice (Coll, Taylor \& Grainger, 2002). Defining what skills are to be assessed is paramount. It is argued that, unless there is explicit assessment of generic skills, the teaching of these skills is unlikely to be given the required attention. A discipline-embedded approach to developing generic skills is favored, but with explicit assessment and reporting of the outcomes.

Binks and Exley (1992) have established a list of twenty-five skills to be considered for WBL Practice. However, the list has often been criticized as some of the skills are seen as being duplicative and confusing. Several other researchers have tried to improve the list (e.g. AGR, 1995; Harvey et al., 1997; Watts and Hawthorn, 1992; Dunne et al., 2000; Lees, 2002). The most widely used one today is from HEA (2006) which identified a list of fourteen transferable skills consisting of (1) imagination/creativity;(2) adaptability/flexibility;(3) willingness to learn;(4) independent working/autonomy; (5) working in a team;(6) ability to manage others;(7) ability to work under pressure;(8) oral communications; (9) communications in writing for varied purposes/audiences;(10) numeracy;(11) attention to detail;(12) time management;(13) assumption of responsibility and for making decisions; and (14) planning, coordinating and organizing ability. The few Universities which attempted to assess transferable skills on WBL practice based themselves on the list developed by HEA. However, they complained that the work is tedious due to the complexity of placement settings rendering the application of the list difficult. However, Hager (2011) were convinced that assessment can make its way in WBL practice based on well referenced competencies and standards. This study envelops the transferable skills defined by previous researchers and attempts to define a fine list of generic transferable skills that may be subject to assessment.

\section{Methodology}

To extract information about acquisition of transferable skills at practice settings and its relevance to assessment, two sets of questionnaires were developed. One was administered to students to extract relevant information about the transferable skills they had experienced during their WBL practice. The second set of questionnaire was destined to mentors who had coached and assessed students during their WBL training. Both questionnaires contained section that included Likert scale questions to rate the degree of importance of transferable skills at practice settings (rating scale 1-5: 1: not important (NI), 2: a little important (LI), 3:Neutral (N), 4:Important (I) - 5:Very Important (V)). The extent students have acquired those skills have also been rated (rating scale 1: Not acquired at all, 2: Acquired a little, 3: Neutral, 4:Acquired to some extent, 5: Acquired Fully). The degree to which those skills are being considered as being generic was also being 
measured using Likert scale as well as their consideration for being subject to assessment. Open-ended questions were also provided for enabling respondents to share their experiences and insights. The mentor's questionnaire was administered to mentors based on probability random sampling technique. The mentors were sorted on a list in alphabetical order and the selection was made by using an integer random generator. On the other hand, the student's questionnaire was stratified over four Faculties of (1) Faculty of Law \& Management (FLM), (2) Faculty of Science (FOS) and (3) Faculty of Social Studies \& Humanities (FSSH) and (4) Faculty of Engineering (FOE). This ensured a good representation of students across the different Faculties.

\section{Results and discussion}

The quantitative data were analyzed using SPSS version 21. Table 1 shows the mean rank of the extent of transferable skills acquisition as experienced by the students and the mentors. Skills such as 'Team Working', 'Planning', 'Listening', 'Oral Communication' have been highly rated by both students and mentors which mean that they are easily accessible at practice settings. While other skills such as 'Negotiation', 'Innovative' and 'Leadership' are not found to be adequately available.

Table 1: Extent transferable skills are being acquired

\begin{tabular}{lll}
\hline Extent of Acquiring & Students Mean Rank & Mentors Mean Rank \\
\hline Team Working & 4.13 & 4.18 \\
Planning & 4.32 & 3.96 \\
Listening & 4.30 & 3.95 \\
Oral Communication & 4.15 & 3.88 \\
Information Technology & 4.07 & 3.89 \\
Self Learning & 4.19 & 3.68 \\
Time Management & 4.17 & 3.63 \\
Problem Solving & 4.14 & 3.59 \\
Professional Development & 4.00 & 3.71 \\
Numeracy & 3.98 & 3.64 \\
Organizational & 3.98 & 3.62 \\
Written Communication & 3.87 & 3.55 \\
Decision Making & 4.03 & 3.38 \\
Negotiation & 3.86 & 3.27 \\
Innovative & 3.82 & 3.25 \\
Leadership & 3.77 & 3.27 \\
Enterprising & 3.25 & 2.85 \\
\hline
\end{tabular}

Table 2: Degree transferable skills are generic

\begin{tabular}{lll}
\hline Degree of being generic & Mean (Students) & Mean (Mentors) \\
\hline Team Working & 4.38 & 4.36 \\
Oral Communication & 4.37 & 4.29 \\
Planning & 4.36 & 4.26 \\
Professional Development & 4.32 & 4.20 \\
Time Management & 4.29 & 4.23 \\
Listening & 4.28 & 4.19 \\
Information Technology & 4.19 & 4.27 \\
Planning & 4.23 & 4.22 \\
\hline
\end{tabular}




\begin{tabular}{lll}
\hline Written Communication & 4.19 & 4.18 \\
Self Learning & 4.26 & 4.04 \\
Problem Solving & 4.26 & 4.04 \\
Decision Making & 4.21 & 4.04 \\
Innovative & 4.22 & 3.90 \\
Numeracy & 4.06 & 4.02 \\
Leadership & 4.07 & 3.88 \\
Negotiation & 4.10 & 3.82 \\
Enterprising & 3.80 & 3.48 \\
\hline
\end{tabular}

As regards to the degree of being generic, it was observed that both mentors and students rated highly skills such as 'Team Working', 'Oral Communication', 'Planning', but provided a lower ranking for skills such as 'Leadership', 'Negotiation' and 'Enterprising' as shown in Table 2. The results obtained were found to match the study conducted by Brown and Ahmed (2009) where the transferrable skills communication, problem solving, team working and time management were ranked high whereas decision making, planning and organising, and management skills were given low ranking. Results were also seen to be compatible to what HEA (2006) proposed where oral communication, written communication, team working and time management form part among the set of transferable skills which are accessible at practice settings. Consideration for assessing these transferable skills under formal assessment was rated by students and mentors. The means and standard deviation of the different transferable skills under test are illustrated in Table 3. Skills such as 'Oral Communication', 'Team Working', 'Planning' were ranked in the first positions while 'Innovative', 'Leadership' and 'Negotiation' were poorly rated. This demonstrates close similarity to the previous two tables indicating that there is close correlation among those transferable skills that may be subject to assessment. The means being higher than 4 indicates in each case as illustrated under Table 3 indicates that both students and mentors were found to be fully agreeable for the application of assessment on these transferrable skills.

Table 3: Consideration for assessment

\begin{tabular}{lllll}
\hline Consideration for assessment & $\begin{array}{l}\text { Student } \\
\text { Mean }\end{array}$ & SD & $\begin{array}{l}\text { Mentor } \\
\text { Mean }\end{array}$ & SD \\
\hline Oral Communication & 4.35 & 0.754 & 4.38 & 0.737 \\
Team Working & 4.35 & 0.713 & 4.35 & 0.731 \\
Planning & 4.25 & 0.784 & 4.23 & 0.883 \\
Written Communication & 4.20 & 0.806 & 4.25 & 0.882 \\
Problem Solving & 4.21 & 0.852 & 4.23 & 0.816 \\
Time Management & 4.20 & 0.840 & 4.18 & 0.845 \\
Information Technology & 4.11 & 0.960 & 4.26 & 0.828 \\
Organizational & 4.10 & 0.789 & 4.14 & 0.946 \\
Professional Development & 4.17 & 0.800 & 4.01 & 0.923 \\
Listening & 4.24 & 0.775 & 3.91 & 0.861 \\
Numeracy & 4.01 & 0.923 & 4.09 & 0.896 \\
Self Learning & 4.20 & 0.835 & 3.87 & 0.901 \\
Decision Making & 4.10 & 0.841 & 3.89 & 0.953 \\
Innovative & 4.09 & 0.853 & 3.75 & 1.047 \\
Leadership & 4.07 & 0.799 & 3.74 & 1.056 \\
Negotiation & 3.95 & 0.854 & 3.64 & 1.056 \\
Enterprising & 3.66 & 1.034 & 3.37 & 1.119 \\
\hline
\end{tabular}


In addition, the order of importance of the different transferable skills was rated by both students and mentors. Factor analysis was used to analyze the importance of these skills in the assessment process. All the items were observed to correlate fairly well with no singularity ( $p$ values $<0.05$ ). Factor extraction revealed that there were three factors that were found to have Eigen values $>1$ which accounted for the total variance as illustrated under Table 4. Varimax Orthogonal Rotation was considered to optimize the factor structure thereby equalizing the importance of the three factors. Based on the rotated component matrix which was obtained after 7 iterations as illustrated in Table 5, the lower rating skills such as listening, professional development and organizational ones were eliminated leaving a concise list of ten transferable skills that was important and accessible at practice settings and what might be subject to assessment. The list derived through factor analysis in fact confirmed what students and mentors found as regards to these transferable skills that may be subject to assessment.

Table 4: Total Variance Explained

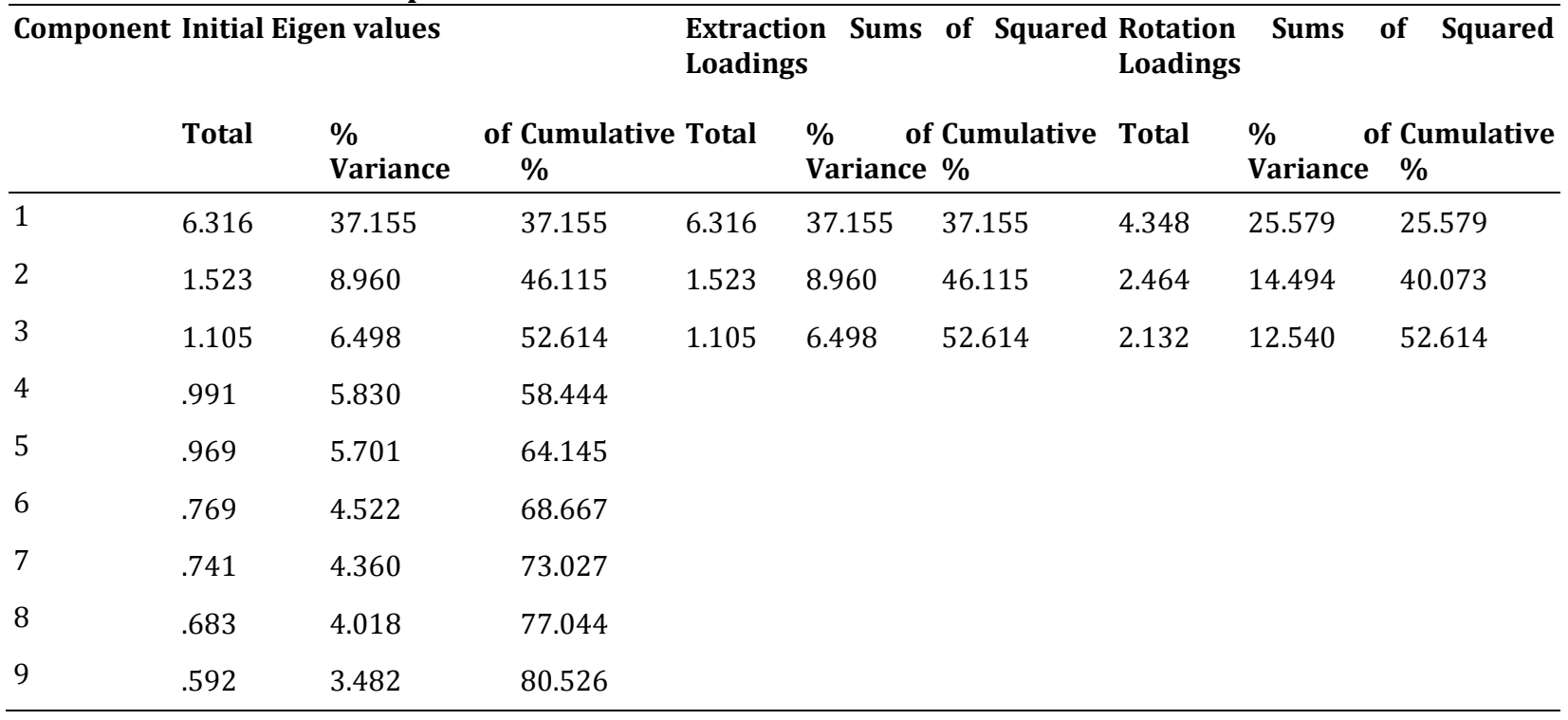

Table 5: Rotated Component Matrix

\section{Component}

\begin{tabular}{|c|c|c|c|}
\hline & 1 & 2 & 3 \\
\hline Oral communication skills. & & & .698 \\
\hline Written communication skills. & & & .792 \\
\hline \multicolumn{4}{|l|}{ Listening skills. } \\
\hline Team working skills. & & .678 & \\
\hline Self learning skills. & & .583 & \\
\hline Problem solving skills. & .636 & & \\
\hline Numeracy skills. & & .649 & \\
\hline Information technology skills. & & .622 & \\
\hline \multicolumn{4}{|l|}{ Professional development skills. } \\
\hline Time management skills. & .519 & & \\
\hline Decision making skills. & .765 & & \\
\hline \multicolumn{4}{|l|}{ Organizational skills. } \\
\hline Planning skills. & .675 & & \\
\hline
\end{tabular}


In addition, there was also need to assess the variability in skills acquisition. This was achieved by considering two hypotheses which were tested to investigate whether transferable skills acquisition (i) differ from public, private and parastatal practice settings and (ii) differ according to gender.

\section{Hypothesis 1}

$\mathrm{H}_{0}$ : There was no significant difference in transferable skills acquired by students among public, private and parastatal bodies

$\mathrm{H}_{1}$ : There was a significant difference in transferable skills acquired by students among public, private and parastatal bodies

Kruskal Wallis which is a non-parametric test was used as the data was not found to be normal. The result revealed that $\mathrm{p}$-value $=0.063>0.05$ indicating that there was no significant difference in skills acquisitions among the various types of practice settings. This provides further evidence that the core transferable skills are accessible at any practice settings which demonstrate further that the application of formal assessment is plausible. In addition, hypothesis was also tested as to whether there was a difference in skills acquisitions as experienced by male and female students.

\section{Hypothesis 2}

$\mathrm{H}_{0}$ : There was no significant difference in transferable skills acquired by male and female students $\mathrm{H}_{1}$ : There was a significant difference in transferable skills acquired by male and female students

The result depicted that $\mathrm{p}$-value $=0.471>0.05$ indicating that there was no significant difference in skills acquisitions between male and female students indicating uniformity in skills acquisitions. The result obtained from both hypotheses further consolidate that these transferable skills may be subjected to assessment as they are found to be location independent i.e. irrespective of the type of practice settings, the assessment made will be similar and in addition it is not influenced by gender i.e. male and female students experience similar acquisition of skills. The following ten transferable skills can therefore be retained for assessing students on their WBL practice (1) Oral communication; (2)Written communication; (3)Team working; (4)Self learning; (5)Problem solving ; (6)Numeracy; (7) Information Technology; (8)Time management; (9)Decision making; (10)Planning. The study provides an improved list over the HEA proposed one. The accessibility and generic nature of these transferable skills will facilitate Universities to standardise assessment in WBL practice. It also helps in meeting the expectation of potential employers as Lowden et al (2011) reported that employers wish that graduates demonstrate a range of broader skills and attributes that include team-working, communication and problem solving.

\section{Conclusion}

The study demonstrates that assessment of WBL practice may be based on transferable skills, as there is a set of skills that are generic, accessible and assessable at practice settings. The list of transferable skills derived from this study has been obtained after considering features such as extent of acquisition, generic nature of skills at practice settings together with the views from those who have experienced formal assessment in WBL practice. The findings have shown that the skills acquisitions are acknowledged by students and mentors. The integration of assessment based on these transferable skills into the undergraduate curriculum is therefore feasible. In fact, it should be encouraged as it reinforces the commitment of students in acquiring the right skills. WBL Practice with assessment adds more value to the knowledge obtained. Based on the outcome of this study, it can be deduced that standardized assessment can definitely make its way in WBL practice. 


\section{References}

AGR. (1995). Association of Graduate Recruiters. Skills for Graduates in the $21^{\text {st }}$ Century, Cambridge: AGR.

Barrie, S.C. (2006). Understanding what we mean by the generic attributes of graduates. Higher Education, $51(2), 215-241$.

Binks, M. \& Exley, K. (1992). Observing the Output of Institutions of Higher Education: The Case of Student Competence, proceedings from Innovative Assessment in Higher Education, pp.51-58

Bridgstock, R. (2009). The graduate attributes we've overlooked: enhancing graduate employability through career management skills. Higher Education Research \& Development, 28(1), 31-44.

Brown, G. \& Ahmed, Y. (2009). The value of work placements. Enhancing the Learner Experience in Higher Education, 1(1), 19-29.

Coll, R. K., Taylor, N. \& Grainger, S. (2002). Assessment of work based learning: some lessons from the teaching profession. Asia-Pacific Journal of Cooperative Education, 3(2), 5-12.

DfES. (2005). Department for Education and Skills, Report of the End to End Review of Careers Education and Guidance, London: Department for Education and Skills.

Dunne, E., Bennet, N. \& Carré, C. (2000). Skill development in higher education and employment. In: Coffield, F. (ed.) Differing visions of a learning society. Research findings, volume I. The Policy Press \& ESRC

Eames, C. (2010). Learning through work placements in science and technology. Unpublished PhD thesis. The University of Waikato, Hamilton, New Zealand.

Fallows, S. \& Stevens, C. (2000). Building employability skills into the higher education curriculum: a university-wide initiative. Education + Training, 42(2), 75-83.

Finch, D. J., Hamilton, L. K., Baldwin, R. \& Zehner, M. (2013). An exploratory study of factors affecting undergraduate employability. Education + Training, 58(7), 681-704.

Hager, P. (2011). Theories of workplace learning, in Malloch, M., Cairns, L., Evans, K. and O'Connor, B.N. (Eds), The SAGE Handbook of Workplace Learning, SAGE Publications Ltd, London, pp. 17-31.

Harvey, L., Moon, S. \& Geall, V. (1997). Graduates' Work: Organizational Change and Students' Attributes. Centre for Research into Quality.

HEA. (2006). Higher Education Academy, York, retrieved from: www.heacademy.ac.uk/resources/publications/learningandemployability, Oct 2015

Johnston, N., Angerilli, N. \& Gajdamaschko, N. (2004). How to measure complex learning processes: The nature of learning in cooperative education. In P. L. Linn, A. Howard \& E.Miller (Eds.), Handbook for research in cooperative education and internships (pp. 157-190). Mahwah, NJ: Lawrence Erlbaum Associates.

Kelly, A. (2001). The evolution of key skills: towards a Tawney paradigm. Journal of Vocational Education and Training, 53(1), 21-35.

Lees, D. (2002). Graduate Employability - Literature Review. LTSN Generic centre. University of Exeter. http://www.palatine.ac.uk/files/emp/1233.pdf

Lowden, K., Hall, S., Elliot, D. \& Lewin, J. (2011). Employers' perceptions of the employability skills of new graduates, Glasgow: Edge Foundation

Nabi, G. R. (2003). Graduate employment and underemployment: opportunity for skill use and career experiences amongst recent business graduates. Education + Training, 45(7), 371-82.

Nunan, T., George, R. \& McCausland, H. (2000). Implementing Graduate Skills at an Australian University, Integrating Key Skills in Higher Education, Kogan Page, London, pp. 57-66.

Oliver, B., Tucker, B., Gupta, R. \& Yeo, S. (2008). E VALUate: an evaluation instrument for measuring students' perceptions of their engagement and learning outcomes. Assessment \& Evaluation in Higher Education, 33(6), 619-630.

Te Wiata, I. (2001). A big ask: To what extent can universities develop useful generic skills? In F.Bevan, C. Kanes, \& D. Roebuck (Eds). Knowledge Demands for the New Economy. Brisbane: Australian Academic Press, pp. 290-297.

Watts, A. G. \& Hawthorn, R. (1992). Careers Education and the Curriculum in Higher Education. NICEC Project Report. Cambridge: Careers Research and Advisory Centre

Zegwaard, K. \& Coll, R. (2011). Using Cooperative Education and Work-Integrated Education to Provide Career Clarification. Science Education International, 22(4), 282-291. 